\title{
The interrelation between industrial culture core values and traditional Chinese culture
}

\author{
Dong Lele
}

Wuhan University of Technology, Politics and Administration Institute, Wuhan, Hubei, China 15927327197@163.com

Key Words: Industrial culture, Traditional Chinese Culture, Culture Correspondence.

\begin{abstract}
China has a long history of industrial culture. There is a similarity between industrial culture core values and traditional Chinese culture. Firstly, this paper analyzed the source and concept of the industrial culture, then introduced the Chinese industrial culture core values and expounded the fit place between China's industrial culture with traditional cultural. Finally we give some advices for the current situation of the construction of China's industrial culture development.
\end{abstract}

\section{工业文化核心价值取向与传统文化价值建构}

\author{
董乐乐 \\ 武汉理工大学政治与行政学院, 武汉, 湖北, 中国 \\ 15927327197@163.com
}

关键词: 工业文化；传统文化；文化契合

摘要: 中国工业文化的历史悠久, 其核心价值观念与中国传统文化价值理念有高度契合的地 方。文章先梳理工业文化的来源及概念，再对中国国工业文化的核心价值进行简单的介绍， 阐述中国工业文化与传统文化价值理念契合的地方, 最后针对中国工业文化的建设现状给出 发展工业文化的建议。

1. 引言

18 世纪中叶, 英国人瓦特改良蒸汽机之后, 引起了由手工劳动向机器生产转变的重大飞 跃。由英国首先开启工业革命的热潮, 随后迅猛发展席卷整个欧洲大陆, 之后工业革命传播 到全球各地，工业文化应运而生。我国在 19 世纪开展的洋务运动，在“师夷长技以制夷”的观 念领导下, 大量引进西方先进技术, 正式揭开了中国工业化的进程。与日新月异的工业化进 程相比, 我国对于工业文化的研究远远赶不上工业发展的要求, 工业文化研究领域还存在着 很多空白。在“中国制造 2025”颁布之后, 工业文化的研究逐渐引起了国内企业与学者的注意。 由于国情以及文化的差异, 国外对于工业文化的研究无法与中国工业的文化建设融为一体。 因此, 亟需对中国工业文化进行深度挖掘, 以期为我国工业发展起到积极的推动作用。中共 十八大明确提出并强调: “建设优秀传统文化传承体系, 弘扬中华优秀传统文化。”立足于中 国传统文化, 研究具有中国特色以及时代精神的工业文化, 既有利于弘扬中国传统文化, 又 有利于实现伟大复兴中国梦。

\section{2. 工业文化概述}

工业文化源于英国的工业革命，历时 200 多年的发展与变革，工业文化已拥有一套有自 
身鲜明特点的文化特征。不同于农业文化，工业文化是伴随着工业历史生产发展，具有明显 的制度、思想、管理特点的文化。而中国的工业文化真正意义上的发展，是在新中国成立后 大规模发展工业之后才开始的。纵观改革开放中国的发展，我国的工业水平已领先于世界大 多数的国家，而工业文化的发展却没有跟上工业发展的脚步。[1]文化强国的“中国道路”当今 世界, 文化软实力的发展在综合国力竞争中的地位越来越突出, 文化软实力的竞争正在成为 国际竞争的热点。“当今时代，文化在综合国力竞争中的地位日益重要。谁占据了文化发展的 制高点, 谁就能够更好地在激烈的国际竞争中掌握主动权。人类文明进步的历史充分表明, 没有先进文化的积极引领, 没有人民精神世界的极大丰富, 没有全民族创造精神的充分发挥, 一个国家、一个民族不可能屹立于世界先进民族之林。”[2]工业文化作为工业发展精髓之所在， 对中国的工业生产以及改革开放的发展具有重要意义。

根据国内学者的研究, 工业文化有各种各样的界定。王新哲认为, 工业文化是工业化进 程中所创造和提炼的文化价值观念的集合，它往往与特殊的时代、特定的人物和特色的行业 活动密切相关, 有着比较丰富的内涵, 体现着地域性和时代性。工业文化是伴随工业化进程 而形成的, 包涵工业发展中的物质文化、制度文化和精神文化。[3]王学秀认为工业文化是人 类在工业社会进程中，通过工业化生产与消费过程逐步形成的共有的价值观、信念、行为准 则及具有工业文明特色的群体行为方式, 以及这些信念和准则在物质上的表现。[4]张心吴从 精神文化的角度认为, 敢为人先的开拓精神、重视科技的创新精神、开放吸纳的进取精神、 脚踏实地的务实精神、为国分忧的兼济精神、勇往直前的奋进精神等是工业文化的主要内涵。 [5]在此, 我们认为中国工业文化主要体现在工业精神、工业发展理念以及工业企业文化三个 方面。

\section{3. 中国工业文化的核心价值取向}

由于每个国家的工业发展状况以及文化基础不同，所以每个国家都有着与众不同的工业 文化。中国的工业文化异彩斑斓, 既有满腔热血的爱国主义又有历史悠久的人本主义。在工 业文化建设过程中，厘清与工业文化紧密相关的核心价值要素，既是工业文化理论研究的基 本任务，也是工业文化建设实践中所必须界定的基本问题。[6]

\section{1 爱国文化}

爱国文化是中国工业文化中一个不可缺少的部分，是中国工业文化的精髓所在。十九世 纪, 在经历两次鸦片战争失败后, 一部分有识之士认识到挽救中国的命运必须要学习西方的 先进技术, 由此展开了以“自强”“求富”为口号的洋务运动。新中国成立后, 为抵制西方帝国 主义的威胁，保卫祖国的安全，在毛泽东同志为核心的领导下，开始了中国自主研制“两弹一 星”的工作。当时的中国落后而又贫穷, 科研条件十分艰苦, 但为了祖国的未来和响应党的号 召, 一大批满怀爱国热情的科学家义无反顾的投身于这场革命中。科学家们紧紧团结在一起, 他们不惧严寒酷暑, 发挥自己的全部力量, 以惊人的速度和毅力创造了“两弹一星”的卓越功 绩。正如邓小平同志所言: “如果六十年代以来中国没有原子弹、氢弹, 没有发射卫星, 中国 就不能叫有重要影响的大国, 就没有现在这样的国际地位, 这些东西反映一个民族的能力, 也是一个民族、一个国家兴旺发达的标志。”特别能吃苦、特别能战斗、特别能攻关、特别 能奉献” 是对载人航天精神的高度概括。改革开放以来, 为了缩小与发达国家的差距, 中国航 天人不舍昼夜的辛勤工作, 始终把国家利益放在首位, 创造出一次又一次的丰功伟绩。爱国 文化始终围绕着中国工业的发展进步，是我国工业文化中最浓墨重彩的一笔。

\section{2 人本文化}

人本文化是一种肯定人的价值，尊重人、重视人的一种精神品质。尽管人本文化一开始 并不是工业社会的典型文化特征，甚至还因为劳资关系问题引发了世界范围内的巨大社会变 
迁，但人本关爱这一基本假设，却随着社会进步在 20 世纪后半期成为工业文化的主流价值。 [7]中国工业企业的人本理念是一个从幼稚到成熟的发展过程, 但尊重人、发展人、理解人的 企业精神始终贯彻在中国工业发展的全过程。如旧中国的荣氏企业, 以人为本是其企业发展 的核心理念。荣氏兄弟关爱和重视员工, 广纳贤才, 开设学堂, 对员工进行教育和培训, 对 员工在生活和经济上给予帮助和扶持。荣氏企业能发展成为当时最大的名族资本企业, 以人 为本的企业精神起着不容忽视的作用。再如现代中国的格力集团始终将以人为本最为其人力 资源理念。坚持“任人为贤, 人尽其才” 的理念, 充分肯定员工的价值, 肯定员工的重要作用, 并以此增强企业的凝聚力, 激发员工的潜力, 为格力集团的发展奠定坚实的人才基础。

\section{3 科学文化}

从工业发展的战略上看, 我国工业文化的科学性主要体现在两个方面: 一是提倡绿色发 展。在绿色发展理念的推动下, 中国大力推动生产方式变革, 加快产业升级, 加快新能源产 业和环保产业的发展, 加强工业污染治理。绿色发展以传统产业为支撑, 以发展绿色新兴产 业为导向, 降低对能源的损耗和生态环境的负面影响。实践证明, 极具科学性、操作性、针 对性的绿色发展道路, 已经成为中国工业发展上一道晴丽的风景线。二是提倡可持续发展。 党的十六大以来, 以胡锦涛同志为核心的党中央提出了科学发展观这一重大战略思想。科学 发展观对工业发展提出的要求是, 要贯穿可持续发展理念, 处理好发展与环境保护的矛盾。 可持续发展要求我们, 既要满足当代人的生存需求, 又不能损害子孙后代的利益, 既要达到 工业发展的目的, 又要保护好人类赖以生存的家园。也就是说, 工业的可持续发展与科学发 展是相辅相成的两部分, 实现了可持续发展也就达到了科学发展目的。

\section{4 合作文化}

“工业社会和农业社会最大的区别，就是人们在逐渐摆脱熟人社会后，和有共同利益的 陌生人合作, 并产生了企业这样管理逐步规范的群体化组织。”[8]首先, 在员工方面。随着工 业化的发展, 生产技术水平不断提高, 企业规模的扩大以及分工越来越精细, 一个企业的人 员也越来越多。企业员工来自五湖四海, 共同为了一个组织中的目标而进行努力, 这种精细 分工的情况下, 对企业内部成员的观念提出了特殊的要求。员工们必须树立一个清醒的认识, 大家只有精诚合作, 才能保持生产的正常运转, 才能实现效率最大化, 个人才能在此条件下 获得更多的利益。[9]其次, 企业之间的利益追求也要求合作。“随着市场竞争的深入和顾客需 求的多样化, 越来越多的企业认识到, 传统的以消灭竞争对手为目标的排他式竞争已经不能给 企业带来成功, 只有基于合作基础上的竞争才有利于企业的长期生存和发展,企业之间通过建 立合作关系寻求共赢已经成为一种趋势.”[10]所以, 在这两个方面的影响, 为了企业的长远发 展和布局, 中国企业始终倡导合作至上, 合作文化因此也成为中国工业文化的一部分。

\section{4. 传统文化与工业文化的契合}

中国传统文化对中国人民有着不可忽视的影响, 中国工业在发展中形成的各种文化, 也 与中国传统文化有着千丝万缕的联系和契合点。

\section{1 爱国如饥渴}

爱国主义文化是中国几千年来绵延不断的探讨主题，是中国人民对于国家的一种责任感 和价值观的体现。中国传统文化具有丰富的爱国主义传统, 虽然在不同的历史时期其表现形 式不同, 但强烈的民族独立意识、民族忧患意识、大无畏的牺牲精神都是爱国主义的真实写 照，一直激励着无数炎黄子孙。[11]在古代，东汉著名的文、史学家班固认为“爱国如饥渴”, 意思是爱国就像人饥渴到一定程度必须要喝水吃饭一样, 要达到极点。“死去元知万事空, 但 悲不见九州同”，爱国诗人陆游在临终之前仍念念不忘祖国的和平统一。“人生自古谁无死， 留取丹青照汗青”, 文天祥认为, 人终有一死, 但如果是为国牺牲, 就死得有意义。在近代中 
国工业发展过程中, 从以“自强求富”为口号的洋务运动, 到现代中国的航天精神、大庆石油 精神都是爱国主义在工业发展发展方面的体现。可以说, 爱国主义文化是中国人民从古至今 一脉相承的宝贵精神, 中国工业文化中的爱国精神, 即体现着中国人民的家国情怀, 也凝结 着中国传统文化的爱国论思想。

\section{2 以人为本}

儒家文化以“仁”“义”为核心，强调人际关系的和谐，主张重义轻利。陈志岁认为：“仁以 处人, 有序和谐, 是孔子思想的原发点, 是儒家思想核心之核心。”所谓“仁者爱人”, 强调仁 爱人人可为, 在仁爱者的眼里, 没有尊卑贵贱之分, 所有人对其他人都应怀抱仁爱之心。荀 子曾经把天地万物分成四类, 他说: “水火有气而无生, 草木有生而无知, 命兽有知而无义, 人有气有生有知，亦且有义，故最为天下贵也”，意思是水火有气息却没有生命，草木有生命 却无知觉, 命兽有知觉却没有道义, 而人兼具气息、生命、知觉且懂仁义, 是天底下最为宝 贵的。中国的工业企业不仅尊重并践行“以人为本”的理念, 建立以人为本的管理体制, 而且 还以工人的利益追求为企业发展的最终动力。同时, 现代工业企业发展以人才竞争为重点, 如何留住人才是企业最为关心的话题。所以中国工业企业在发展中越来越注重“人”的作用, 这种对人本主义的践行同中国文化的“民为贵”的基本观念具有极大相似性和一致性。

\section{3 道法自然}

道家学说以“道”为最高哲学范畴, 用“道”来诠释自然、社会、人生之间的关系。道家提 倡“道法自然”，主张崇尚自然，遵循万事万物发展本身规律，人应该法天、法地、法自然。

《庄子·齐物论》提出, “天地与我并生, 而万物与我为一。”在道家思想中, 人与天地万物生 死并存, 共同构成一个有机整体。再者, “天人合一”的思想, 强点人与自然的和谐统一, 人 必须遵循自然的法则, 合乎自然的法则, 才能为自然所接受。老子在《道德经》第三十七章 提出“道常无为而无不为。”这是说, 道永远是顺应自然而无所作为的, 却又没有什么事情不 是它所作为的。这里是指, 道是产生宇宙万物的本体, 在产生过程中, 是自然而发生的, 没 有任何外在附加的力量, 但万物却是由道而生。“无为而无不为”, 并不是提倡什么都不做, 而是说按照自然规律和逻辑发展和变化, 不去过多强求。过去工业发展给环境带来了严重的 污染, 人们在重新审视自己的作为之后, 对环境的珍视多过于对工业发展的追求。中国自古 依赖提倡顺应自然发展的规律, 不与自然相对抗, 所以中国经历了从注重工业发展到注重生 存环境的一个递进过程, 绿色与环保也成为中国工业发展中一个重要的话题。中国的工业发 展提倡绿色、环保、和谐的理念, 既是对自然规律的尊重, 也是对“天人合一”思想的继承和 发展。

\section{4 兼相爱交相利}

墨家以“兼爱”为思想核心，主张无差别、不分彼此、无亲疏之别的博爱。墨子主张“兼相 爱, 交相利”, 他认为当时社会国与国之间的战争与争夺是因为人们互相的不相爱。墨子认为, 爱与利是相辅相成、互为条件的。墨子“兼相爱交相利”思想之实质，主张人们相亲相爱，消 除人际关系中不友好的一面, 创造良好的社会交往关系, 使人们在相爱的基础上, 满足大家 的利益要求。中国工业快速发展的原因, 一方面在于企业强调内部人员的合作。集体合作的 精神是世界所公认的提高效率和生产力的最基本因素, 传统文化要求为整体利益奉献的精神 与人本管理中集体合作精神、团队精神是一致的。[12]另一方面在于企业与其他企业、其他 国家之间的相互合作。如中国提出的“一带一路”发展战略, 就是中国充分利用与其他国家的 多边机制, 高举和平发展的旗帜, 与其他国家共同打造的政治互信、经济融合、文化包容的 利益共同体、命运共同体和责任共同体。中国人向来提倡能够“和气生财”的理念, 在利益面 前强调合作概念，所以合作文化也是中国工业一个重要的文化特征。 


\section{5. 对中国工业文化发展的建议}

\section{1 根植于优秀传统文化, 建立文化自信。}

建设具有强大生命力的工业文化, 必须要体现中华民族的特殊, 具有中国风格、中国特 征。首先, 我们要根植于优秀传统文化, 以此作为工业文化建设的思想基础, 发扬中国风格。 对于传统文化, 我们要用一分为二的观点, 取其精华, 去其糟粕, 使其能为当代文化建设服 务。儒家文化中还提倡淡泊名利、积极入世等道德观念。这些观念随着社会的发展进步, 早 已根植于中国民族的心中, 并在推动中国文化的发展起着重要的作用。其次, 建设具有中国 特色的工业文化，必须立足于马克思主义的指导思想，坚持中国工业文化的社会主义方向。 邓小平理论和“三个代表”重要思想是马克思主义中国化的重要体现, 是对中国优秀传统文化 的继承和发展。工业文化作为中国特色社会主义文化的重要组成部分, 必须以邓小平理论和 “三个代表”重要思想为指导思想, 才能使传统文化与工业文化有效结合, 创造中国文化的新 辉煌。

\section{2 吸收和借鉴世界各国一切优秀文化成果。}

在全球经济一体化的浪潮推动下, 当今世界的任何一个民族和国家的发展, 都与其他国 家或民族建立了密切的联系, 都不可能独立于其他国家孤立发展。西方的工业文化, 自从工 业革命以来, 就一直处于世界领先水平。西方工业文化如此发达的原因, 除了西欧是工业革 命的发源地以外, 更多的受古希腊文化的影响。首先, 西方的文化发源于以形式逻辑为基础 的古希腊文明上, 这是一种极赋数理性的文化, 为工业文化的发展提供了理论基础。其次, 希腊位于欧洲南部的巴尔干半岛南端, 希腊群岛由于特殊的地理位置, 物产缺乏, 人民为了 生存与发展, 曾形成了世界上堪称发达的外向型经济。相对于中国内陆文明, 西方国家由于 其散落的城邦制, 更具创新精神。在这种文化氛围的发展下, 西方自工业革命开始便在世界 舞台上大放异彩。中国文化尚来具有宽容开放的特点, 我们要利用此优势, 充分发掘吸收西 方国家的优秀工业文化, 学习西方先进文明的研究探索方法, 吸取西方工业文化中的养分, 为我国工业文化发展而用。中国在 20 世纪中叶, 先是实行“一边倒”政策,全盘学习苏联, 后又 实行“超英赶美”的发展战略。历史已经证明, 全盘照搬的模式注定不能成功。[13]所以我们必 须在辩证观的指导下, 对外来文化不全部肯定, 也不全部否定。我们必须结合中国发展的实 际情况，充分考虑中西政治、经济、文化方面的差异，坚持“三个有利于”的标准，在批判中 继承, 使之为我国工业文化的发展服务。

\section{3 与先进的时代精神相结合。}

从人类文化发展的历史看,世界上许多文化发祥地和它所创造的辉煌文化,随着历史的擅 变而先后渐趋势微,如古埃及文化、玛雅文化,自我封闭、缺乏创新、固守僵化是这些文化走向 没落与衰亡的重要原因之一。而只有中国文化如涛涛江河川流不息, 不断发展,绵延几千年而不 衰, 具有无限的生命力, 就是因为它具有与时俱进的理念, 具有强大的整合创新能力。[14]科学技 术与文化发展是相互影响的两个方面。首先, 科学技术的发展推动文化的变革。科学技术的 不断更新创造, 使人们的生产生活方式以及价值观都发生了巨大的变化。若我们的文化不及 时的更新换代, 势必会阻碍社会前进的脚步。其次, 文化推进科学技术的进步。工业文化成 果主要是由工业文化成果主要是由工人阶级和劳动群众创造出来的, 凝结着他们的丰富的经 验和智慧结晶, 是一笔宝贵财富。[15]我们要在工业发展的历史中, 积极吸取其宝贵的思想 精华, 将工人们总结出来的宝贵经验, 结合时代发展的需要, 将其上升到理论层面, 从而对 科学技术的更新起到推动和促进的作用。

\section{References}

[1]Wang Xinzhe,Zhou Rongxi.Review of industrial culture[J].Journal of Harbin Institute of 
Technology(Edition of Social Sciences ),2015,17(01):88-93.

[2]Ren zhongping. The Chinese way of cultural power[N].People's Daily,2011-10-15(001).

[3]Wang Xinzhe,Sun xing.A preliminary exploration of the concept, scope and framework of industrial culture[J].Journal of Northwestern Polytechnical University(Edition of Social Sciences ),2015,35(01):30-33.

[4][6][7][8]Wang Xuexiu,Han Chengxia,Zhang Xiaoxi. The analysis of several basic problems of industrial culture[J].Enterprise culture,2016,(03):21-24.

[5]Zhang Xinhao,etc.Initial Exploration of Tangshan Industrial Culture [J] .Journal of Tangshan College ,2005(06).

[9]Han Shujin.Discussion on the construction of corporate culture[J].Enterprise Vitality,2007,(12):61-62.

[10]Wu Zhiwei,Mao Ning,Chen Ying.Empirical research on the influence mechanism of corporate cooperation performance[J]. Management World, 2005,(9): 99- 106.

[11]Zhang hongxia.The basic spirit and contemporary inheritance of traditional Chinese culture[J].Journal of China University of Petroleum(Edition of Social Sciences),2013,29(01):91-96.

[12]Wang Rui.The interrelation between Chinese traditional culture and modern enterprise culture in China[D].Xidian University ,2006.

[13]Liu Dexi.The path of Beyond western civilization[J].New vision,2007,(01):10-16.

[14]Deng Hongyan.Discuss the spirit of Chinese traditional culture .Journal of Hunan Economic Management College. In 2005 Phase II.

[15]Huang Haifeng. The epistemological basis and enlightenment of the construction of industrial culture [J].Theoretic Observation,2015,(12):18-19. 